\title{
Microplastic fibers influence Ag toxicity and bioaccumulation in Eisenia andrei but not in Enchytraeus crypticus
}

Paula S Tourinho ( $\sim$ paulatourinho@gmail.com )

University of Chemistry and Technology Prague: Vysoka skola chemicko-technologicka v Praze https://orcid.org/0000-0003-3941-9522

Susana Loureiro

University of Aveiro: Universidade de Aveiro

VSSL Prasad Talluri

University of Chemistry and Technology Prague: Vysoka skola chemicko-technologicka v Praze

Andraž Dolar

University of Ljubljana: Univerza v Ljubljani

Rudo Verweij

Vrije Universiteit Amsterdam

Jiří Chvojka

Technical University of Liberec: Technicka Univerzita v Liberci

Alena Michalcová

University of Chemistry and Technology Prague: Vysoka skola chemicko-technologicka v Praze

Vladimír Kočí

University of Chemistry and Technology Prague: Vysoka skola chemicko-technologicka v Praze

Cornelis A.M. van Gestel

Vrije Universiteit Amsterdam

\section{Research Article}

Keywords: chronic toxicity, earthworms, enchytraeids, polyester, FTIR

Posted Date: February 16th, 2021

DOI: https://doi.org/10.21203/rs.3.rs-191641/v1

License: (c) (1) This work is licensed under a Creative Commons Attribution 4.0 International License.

Read Full License 


\section{Abstract}

Microplastic fibers (MF) are released from synthetic textiles during washing and end up in the wastewater. Similarly, silver nanoparticles (AgNP), incorporated in textiles as antimicrobial agents, are released in washing machines, also reaching the wastewater treatment plants. Therefore, both MF and AgNP co-exist in the environment, and enter the soil compartment mainly via the application of biosolids. Yet, the combined effect of MF and AgNP has not been studied. Here, we assessed the effects of polyester MF $\left(0.01 \%\right.$ DW) on the toxicity of $\operatorname{AgNP}(32,100,320,1000,3200 \mathrm{mg} \mathrm{Ag} / \mathrm{kg})$ and $\mathrm{AgNO}_{3}(12.8$, $32,80,200,500 \mathrm{mg} \mathrm{Ag} / \mathrm{kg}$ ) to the earthworm Eisenia andrei and the enchytraeid Enchytraeus crypticus. The exposure to MF caused a decrease in the number of juveniles and changed the biochemical composition of earthworms. Moreover, the presence of MF increased the toxicity of AgNP to earthworm reproduction ( $\mathrm{EC50}=165 \mathrm{mg} \mathrm{Ag} / \mathrm{kg}$ ) when compared to AgNP exposure alone (EC50 = $450 \mathrm{mg} \mathrm{Ag} / \mathrm{kg}$ ), but did not alter the toxicity of $\mathrm{AgNO}_{3}(\mathrm{EC} 50=40 \mathrm{mg} \mathrm{Ag} / \mathrm{kg}$ ). For enchytraeids, no significant difference in Ag toxicity could be detected when MF was added to the soil for both $\mathrm{AgNP}$ and $\mathrm{AgNO}_{3}$. Overall, $\mathrm{Ag}$ bioaccumulation was not affected by MF, with the exception of a decrease in earthworm body concentration at the highest $\mathrm{Ag}$ soil concentration (3200 mg Ag/ $\mathrm{kg}$ ). Our results suggest that the presence of MF in the soil compartment may be a cause of concern, and that the joint exposure to $\mathrm{Ag}$ may be deleterious depending on the Ag form, organism and endpoint. The present work provides the first evidence that a realistic MF concentration in soil lowers AgNP concentration necessary to provoke reproductive impairment in earthworms. The influence of MF on risk assessment of AgNP should be considered.

\section{Introduction}

Recently, the contamination of the soil compartment by microplastics has been recognized as an issue of concern. Studies have shown the ubiquitous presence of microplastics in soils, which can vary among sites with different land-uses. For example, floodplain sites in Switzerland had an average microplastic concentration of $0.0005 \%$ dry weight (DW), with the most contaminated site containing $0.0055 \%$ (DW) (Scheurer \& Bigalke, 2018), equivalent to 5 and $55 \mathrm{mg} / \mathrm{kg}$, respectively (Scheurer \& Bigalke, 2018). In industrial areas in Australia, microplastic concentrations varied from 0.03 to $6.7 \%$ (DW) (Fuller \& Gautam, 2016). Different sources can contribute to the increasing concentration of microplastics in the terrestrial compartment, such as local deposition of waste and atmospheric deposition. Nevertheless, the main source is believed to be the land application of biosolids from wastewater treatment plants (WWTP) (Ng et al., 2018; Horton et al., 2017b).

One major contributor to the microplastic pollution is the release of fibers from synthetic textiles (Browne et al., 2011; Horton et al., 2017a). During the washing process, microplastic fibers (MF) can be released from households to wastewater (Sillanpää Markus \& Sainio, 2017; Pirc et al., 2016; Hernandez et al., 2017). Therefore, MF reaches the WWTP and are also believed to reach soils via biosolids application (Nizzetto et al., 2016). Even their presence can be used as an indicator of sludge application on soil over the years (Zubris \& Richards, 2005). A study in a Canadian WWTP, for example, showed that $98 \%$ of 
microplastics are retained in sludge with the majority (70\%) being represented by fiber-shaped fragments (Gies et al., 2018).

The presence of MF can affect soil properties, including soil water holding capacity (de Souza Machado et al., 2018), bulk density (de Souza Machado et al., 2018), and porosity (Zhang et al., 2019). Another important aspect is the potential of microplastics to act as sorbents for contaminants in soil. The distribution of chemicals to microplastics varies, depending especially on the chemical partitioning coefficients to soil and microplastics as well as the mass of microplastics (Tourinho et al., 2019). With the increasing input of MF to soils, the chances of MF to act as an extra route of exposure to organisms may also increase. Nevertheless, the majority of studies on this topic have been conducted with marine invertebrates (Ribeiro et al., 2019), and there is a lack of studies on the combined effects of MF and chemicals onto soil organisms.

Contaminants having a similar pathway to MF are likely to coexist and interact with MF in the environment. This includes silver nanoparticles (AgNP) which are applied to textiles because of their antimicrobial properties (Durán et al., 2007). AgNP are also released during the washing of textiles (Mitrano et al., 2014), ending up in the sludge of WWTP. Therefore, AgNP present a similar pathway as MF, reaching soils via biosolids application (Whiteley et al., 2013). Although predicted environmental concentrations for AgNP reach maximum values in soils in the $\mathrm{ng} / \mathrm{kg}$ range (Wigger et al., 2015), total $\mathrm{Ag}$ concentration in sludge from municipal WWTP can be as high as $200 \mathrm{mg} \mathrm{Ag} / \mathrm{kg}$ (USEPA, 2009). Moreover, AgNP continuously release Ag ions into soil porewater (Diez-Ortiz et al., 2015), and therefore, it is likely that ionic Ag also co-exist with MF.

In this context, we aim at evaluating the effects of polyester MF on the toxicity of AgNP and the ionic counterpart $\mathrm{AgNO}_{3}$ to the earthworm Eisenia andrei and the enchytraeid Enchytraeus crypticus, using an environmentally relevant MF concentration of $0.01 \%$ DW. Earthworms and enchytraeids have different traits and, therefore, the influence of MF on Ag toxicity may differ between them. Polyester was selected as being the main plastic material used in fiber production (Geyer et al., 2017). Standard reproduction tests were performed with $\mathrm{AgNP}$ and $\mathrm{AgNO}_{3}$ in the absence or presence of MF.

It has been previously shown that microplastics can adsorb AgNP and ionic Ag (Khan et al., 2015; Kalčikova et al., 2020; Li et al., 2020), and that micro- and nanoplastics increase the toxicity of Ag to aquatic organisms (Khan et al., 2015; Monikh et al. 2020). This study is, however, the first report on the combined toxicity of Ag and MF to soil invertebrates.

\section{Methodology}

\subsection{Test chemicals}

AgNP (99.5\% trace metal basis, CAS 7440-22-4) and $\mathrm{AgNO}_{3}$ ( $\geq 99 \%$ purity, CAS 7761-88-8) were purchased from Sigma-Aldrich. The nanoparticles were provided as nanopowder with particle size $<100$ $\mathrm{nm}$, coated with polyvinylpyrrolidone (PVP). The nanoparticle morphology was investigated by 
transmission electron microscopy (TEM), using a JEOL 2200 FS microscope. A dispersion of AgNP in water was deposited on a holey carbon coated Cu TEM grid and dried at room temperature before examination. The TEM images showed that the AgNP have a spherical-like shape (Figure SI1).

To produce the MF, a continuous filament yarn was used. The polyester yarn was transparent in color and had a diameter of $400 \mu \mathrm{m}$ (Korálky Katlas). The yarns were initially cut in smaller filaments with a length of about $1 \mathrm{~mm}$ and subsequently milled in a centrifugal mill (Cryomill by Retsch). Milling conditions were set as $8 \times 45$ s (cycles - time) with 15 s homogenization between the cycles. The final fibers were analyzed by TESCAN VEGA-3 LMU scanning electron microscopy (SEM).

\subsection{Test organisms}

The earthworm Eisenia andrei and the enchytraeid Enchytraeus crypticus were cultured at the Vrije Universiteit (Amsterdam, The Netherlands). Earthworms were kept at $20^{\circ} \mathrm{C}$ in containers containing a mixture of $1: 1$ potting soil and peat with a teaspoon $\mathrm{CaCO}_{3}$ to adjust the $\mathrm{pH}$ and were fed once a week with horse manure free of any pharmaceuticals. Enchytraeids were kept on agar prepared with soil extract at $16^{\circ} \mathrm{C}$, and fed once a week with a mixture composed of oatmeal, dried yeast, yolk powder and fish oil. The cultures were maintained at a controlled photoperiod of $16 \mathrm{~h}$ light/8h dark, however the animals were cultured in darkness to avoid any stress caused by light, especially for enchytraeids, which are kept on agar. Only sexually mature animals of similar age were used in the experiments (i.e., totally developed clitellum). Earthworms were acclimated in LUFA 2.2 soil for one day before starting the exposures.

\subsection{Spiking procedure}

The standard natural LUFA 2.2 soil (Speyer, Germany) was used in the toxicity tests and characterized as sandy loam with an organic carbon content of $1.7 \pm 0.3 \%, \mathrm{pH}\left(0.01 \mathrm{M} \mathrm{CaCl}_{2}\right)$ of $5.6 \pm 0.4$, cation exchange capacity of $9.2 \pm 1.4 \mathrm{cmol}_{\mathrm{C}} / \mathrm{kg}$ and water-holding capacity (WHC) of $44.8 \pm 2.9 \mathrm{~g} / 100 \mathrm{~g}$. Soil was firstly spiked with different concentrations of $\mathrm{AgNP}$ or $\mathrm{AgNO}_{3}$, followed by the addition of MF to half of the $\mathrm{Ag}$ spiked soils. The concentrations of Ag were chosen based on the studies by Diez-Ortiz et al. (2015) and Topuz \& van Gestel (2017). AgNP were added as dry powder, resulting in nominal concentrations of 32 , $100,320,1000$, and $3200 \mathrm{mg} \mathrm{Ag} / \mathrm{kg}$ dry soil. For $\mathrm{AgNO}_{3}$, stock solutions were prepared with Milli-Q® water, and added to the soil to reach nominal concentrations of $12.8,32,80,200$, and $500 \mathrm{mg} \mathrm{Ag} / \mathrm{kg}$ dry soil. The soils were manually mixed, and Milli-Q® water was added to reach a moisture content equivalent with $50 \%$ of the maximum water holding capacity $\left(\mathrm{WHC}_{\max }\right)$. Control soils were also prepared by adding Milli-Q® water at $50 \% \mathrm{WHC}_{\max }$.

After the addition of Ag, the soils were divided in two parts. One part of the soil was spiked with MF at $0.01 \%$ DW. This method was chosen in order to avoid different exposure levels of MF among treatments due to a possible non-homogeneous distribution of the MF in the soil. The soil was again rigorously mixed and left to equilibrate for one or two days before the experiments with earthworms or enchytraeids, respectively. Tests with the single and combined MF and Ag treatments were run simultaneously to 
ensure a proper comparison. The $\mathrm{pH}$ of freshly spiked soils $(5 \mathrm{~g})$ was measured in $0.01 \mathrm{M} \mathrm{CaCl}_{2}$ solution $(25 \mathrm{~mL})$, after shaking for $2 \mathrm{~h}$ and left to settle overnight. Soil samples were kept at room temperature for the quantification of MF in soil or at $-20^{\circ} \mathrm{C}$ for total $\mathrm{Ag}$ analysis.

\subsection{Toxicity tests}

\section{Earthworm reproduction test}

The test was adapted from the OECD guideline $\mathrm{n}^{\circ} 222$ (OECD, 2004a). Approximately $400 \mathrm{~g}$ moist spiked soil, $10 \mathrm{~g}$ horse dung and 10 adult earthworms (individual masses between 250 and $500 \mathrm{mg}$ ) were added to $1000 \mathrm{~mL}$ glass jars. For controls and treatments, 5 and 3 replicates were used, respectively. Animals were kept at $20^{\circ} \mathrm{C}$ and $16 \mathrm{~h} / 8 \mathrm{~h}$ light cycle. Water loss was replenished with deionized water weekly, and additional food was given after 2 weeks if necessary. After 4 weeks of exposure, surviving adults were collected from the jars, washed, blotted dry on filter paper and weighted. Worms were placed in Petri dishes with moist filter paper for one day to purge their gut, and then frozen at $-20^{\circ} \mathrm{C}$. The soils were incubated for another 4 weeks, and at the end of this period, the number of juvenile earthworms emerging from the soil after incubation in a water bath at $60^{\circ} \mathrm{C}$ was recorded.

\section{Enchytraeid reproduction test}

The test was adapted from the OECD guideline $n^{\circ} 220$ (OECD, 2004b). Ten adult enchytraeids were added to test jars containing approximately $25 \mathrm{~g}$ moist soil and $2 \mathrm{~g}$ oatmeal as food. Four replicates were used per treatment and control. The animals were kept in the same conditions as described for the earthworms. Water and food were replenished weekly. After 3 weeks, adults were collected from soil, washed in distilled water and frozen at $-20^{\circ} \mathrm{C}$. Bengal rose and ethanol were added to the soils. After incubation at $4^{\circ} \mathrm{C}$, the juveniles were collected from the soils by sieving and placed in a tray. Pictures were taken and further treated using Photoshop C6 (Adobe) for counting the number of juveniles.

2.5 Quantification of microplastic fibers in soil

Control soil samples were checked for the presence of MF, using a method adapted from Selonen et al. (2020). Briefly, MF were isolated from the soil samples $(0.1 \mathrm{~g})$ manually using tweezers, at the same time

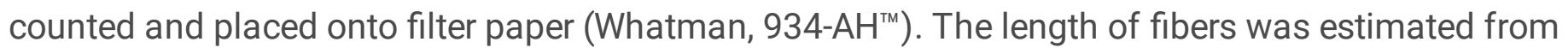
stereo microscope Leica MZ FLIII (Leica, Germany) images using Axio Vision 4.8.2 Software.

\subsection{Total Ag analysis}

For total Ag analysis, soil samples $(n=2)$ were dried for $8 \mathrm{~h}$ at $70^{\circ} \mathrm{C}$ and weighted (approximately $130 \mathrm{mg}$ ) and earthworms were freeze-dried for $48 \mathrm{~h}$ and individually weighted. Soil and earthworm samples were digested in $2 \mathrm{~mL}$ of a mixture of concentrated $\mathrm{HCl}$ (Merck Emparta, purity 37\%) and $\mathrm{HNO}_{3}$ (Merck Emsure, purity $65 \%)(4: 1, \mathrm{v} / \mathrm{v})$ for $7 \mathrm{~h}$ in an oven (Binder ED 53 ) at $140^{\circ} \mathrm{C}$, using tightly closed Teflon containers. After digestion, the soil and earthworm samples were taken up in 10 or $6 \mathrm{~mL}$ of demineralized water, respectively, and analyzed by flame Atomic Absorption Spectrometry (AAS; PerkinElmer AAnalyst 100). 
Certified reference material DOLT-4 was used to ensure the accuracy of the analytical procedure. Ag concentration in the reference material was $85 \pm 24 \%$ (mean $\pm S E$ ) of the certified value.

For extracting soil porewater, at the beginning of the exposures soil samples were saturated with Milli-Q® water. After 7 days of equilibration, samples were centrifuged at 2000 RCF for 25 min and filtered over a 0.45 um filter. Filters were pre-treated with $0.1 \mathrm{M} \mathrm{Cu}\left(\mathrm{NO}_{3}\right)_{2}$ to avoid Ag sorption (Cornelis et al., 2010). Samples were analyzed by flame AAS (Agilent $280 \mathrm{fs}$ AAS).

The enchytraeids were freeze-dried for $24 \mathrm{~h}$ and weighted individually. The samples were digested in 300 $\mu \mathrm{L}$ of a mixture of $\mathrm{HNO}_{3}$ (67-69\%; Fisher Chemical Optima Grade) and $\mathrm{HCLO}_{4}(70 \%$; JT. Baker Ultrex II Ultra Pure Reagent), in the ratio 7:1 and evaporated to dryness. The residues were taken up in $0.5 \mathrm{~mL} 1 \mathrm{M}$ $\mathrm{HCl}$. Silver content was determined by graphite furnace AAS (PerkinElmer, Singapore). Recovery of Ag in the reference material (DOLT-4) was $80 \pm 1.9 \%$ (mean \pm SE) of the certified value.

\subsection{Fourier Transform Infrared (FTIR) Spectroscopy}

MF was characterized by FTIR spectroscopy using a Nicolet 6700 (Thermo Nicolet Corp., Madison, WI). The samples were homogenously crushed with potassium bromide salt $(\mathrm{KBr})$ using mortar and pestle and make them into disks (using a hydraulic press). In order to assess any biochemical modification caused by MF and Ag exposure, freeze-dried earthworms exposed to control, MF, and the combination of MF with AgNP (3200 mg Ag/kg) or $\mathrm{AgNO}_{3}(200 \mathrm{mg} \mathrm{Ag} / \mathrm{kg}$ ) were also analyzed, prepared in the same manner as the MF. The analysis was carried out at a $4 \mathrm{~cm}^{-1}$ resolution within the $4000-400 \mathrm{~nm}$ range. The OMNIC 8 software was used for spectral acquisition.

\subsection{Data analysis}

Performances of the controls from the tests with and without MF were compared by a t-test. LC50s and EC50s were calculated using Probit analysis and a 3-parameter logistic curve, respectively. The EC50s between treatments were compared by a generalized likelihood ratio (GLR) test. A t-test was applied to compare Ag body concentrations in worms exposed in the absence or presence of MF, within the same Ag exposure level. Statistical tests were performed in SPSS Statistics 24 (IBM Corporation).

\section{Results}

\subsection{Microplastic fibers characterization}

SEM images of the MF confirmed the presence of elongated fibers as well as irregular shapes after the cryo-milling process (Figure SI2). FTIR analysis was performed to define the composition of polyester (Figure SI2). A peak at $1732 \mathrm{~cm}^{-1}$ can be attributed to the carbonyl group, shown by the $\mathrm{C}=0$ vibration. Bands around $1730 \mathrm{~cm}^{-1}$ indicate the presence of the ester group, confirming the material as polyester (Dholakiya, 2012; Rosu et al., 2008). 
MF were successfully found in the $0.1 \mathrm{~g}$ samples of spiked soils, indicating a fair distribution of the fibers in soil. Average numbers of MF in the MF control soils of AgNP ( $\pm S D ; n=70)$ and $A N_{3}( \pm S D ; n=60)$ experiments were $116 \pm 34$ and $119 \pm 59$ fibers/g soil and MF lengths were $820 \pm 730$ and $770 \pm 740 \mu \mathrm{m}$, respectively. The size distribution of MF varied from approximately 50 to $3000 \mu \mathrm{m}$, with almost half of the fibers having a size between 100 and $500 \mu \mathrm{m}$ (Figure SI3).

\subsection{Ag content in soil and porewater}

Soil $\mathrm{pH}_{\mathrm{CaCl} 2}$ varied from 5.4 to 5.8 among treatments, with no influence of $\mathrm{Ag}$ concentration, $\mathrm{Ag}$ form or MF presence. Total Ag concentrations in soil overall were between 72 and $100 \%$ of the nominal concentrations (Table SI1). The low recovery (<20\%) observed in soil spiked with AgNP at $3200 \mathrm{mg} \mathrm{Ag} / \mathrm{kg}$ probably is an artefact as porewater concentrations (Table SI2) and responses of the test organisms (body Ag concentrations in earthworms and enchytraeids in Figure 2, and earthworm avoidance behavior in Figure SI4) were consistent with a dose-related pattern. All toxicity results are expressed using the nominal concentrations.

Porewater concentrations were lower than the detection limit $(0.01 \mathrm{mg} \mathrm{Ag} / \mathrm{L})$ in AgNP spiked soils up to $100 \mathrm{mg} \mathrm{Ag} / \mathrm{kg}$ (Table SI2). Above this concentration, Ag porewater was detected but still low values (0.05 $\mathrm{mg} \mathrm{Ag} / \mathrm{L}$ ) were observed even at $3,200 \mathrm{mg} \mathrm{Ag} / \mathrm{kg}$, which were similar in soils with or without MF. For $\mathrm{AgNO}_{3}$, porewater concentration in control soil and soil spiked at $12.8 \mathrm{mg} \mathrm{Ag} / \mathrm{kg}$ were lower than the detection limit, while values close to the detection limit ( 0.01 to $0.03 \mathrm{mg} \mathrm{Ag} / \mathrm{L}$ ) were observed in soils spiked up to $80 \mathrm{mg} \mathrm{Ag} / \mathrm{kg}$ (Table SI2). At nominal concentrations of 200 and $500 \mathrm{mg} \mathrm{Ag} / \mathrm{kg}$, porewater concentrations were 0.29 and $13.6 \mathrm{mg} \mathrm{Ag} / \mathrm{L}$, respectively. When MF were added to these soils, $\mathrm{Ag}$ porewater slightly decreased to 0.27 and $10.6 \mathrm{mg} \mathrm{Ag} / \mathrm{L}$, respectively.

\subsection{Toxicity outcomes}

\subsubsection{Earthworm reproduction test}

The earthworm reproduction test met the validity criteria according to OECD (2004a); in the control soils, adult survival was $100 \%,>30$ juveniles per vessel were counted, and coefficient of variation for juvenile number was $<30 \%$.

In order to assess effects of the MF on survival and reproduction of the test organisms, a comparison was made between control groups from tests performed simultaneously in the absence and presence of MF. Earthworm survival did not differ between groups, with $100 \%$ survival in all controls. However, the presence of MF slightly decreased the number of juveniles per test jar. In the AgNP test, juvenile number ( mean $\pm S E ; n=4$ ) decreased from $40 \pm 3.1$ to $35 \pm 3.7$ when MF was added to the AgNP control soil. This decrease was, however, not significant (t-test, $\mathrm{t}=1.0, \mathrm{p}=0.31$ ). In the $\mathrm{AgNO}_{3}$ test, the number of juveniles significantly decreased from $34 \pm 1.6$ to $22 \pm 2.1$ with the addition of MF ( $t$-test, $t=3.9, p=0.006$ ). 
The LC50 and EC50 values for the effects of $\mathrm{AgNP}$ or $\mathrm{AgNO}_{3}$ in the presence and absence of MF can be found in Table 1 (dose-response curves are shown in Figure SI5). AgNP caused no significant mortality up to $3200 \mathrm{mg} \mathrm{Ag} / \mathrm{kg}$. For $\mathrm{AgNO}_{3}$, the LC50 value was higher in the presence than in the absence of MF. The EC50 for AgNP significantly decreased from $450 \mathrm{mg} \mathrm{Ag} / \mathrm{kg}$ to $165 \mathrm{mg} \mathrm{Ag} / \mathrm{kg}$ when MF was added to the soil (GLR test, $X_{d f=1}^{2}=4.02, p<0.05$ ). Even though the $E C 50$ for $\mathrm{AgNO}_{3}$ was not affected by MF presence (GLR test, $X_{d f=1}^{2}<3.84$, n.s.), a total reproductive failure was observed at 200 in the absence of $\mathrm{MF}$ and at $500 \mathrm{mg} \mathrm{Ag} / \mathrm{kg}$ in the presence of MF.

The FTIR spectra of earthworms are shown in Figure 1 (for peak wavenumbers, see Figure SI6). Compared to the control, the intensity of bands increased in worms exposed to only MF and the combination of $\mathrm{MF}_{\text {with }} \mathrm{AgNO}_{3}(200 \mathrm{mg} \mathrm{Ag} / \mathrm{kg}$ ) and $\mathrm{AgNP}(3200 \mathrm{mg} \mathrm{Ag} / \mathrm{kg})$. An increase in proteins (3300, 1650, $\left.1544 \mathrm{~cm}^{-1}\right)$, lipids $\left(2918 \mathrm{~cm}^{-1}\right)$, and polysaccharides such as carbohydrates $\left(1080 \mathrm{~cm}^{-1}\right)$, glycogen and nucleic acids $\left(1100 \mathrm{~cm}^{-1}\right)$, was observed.

\subsubsection{Enchytraeid reproduction test}

The validity criteria was met in the enchytraeid reproduction test (OECD, 2004b): adult survival was $>80 \%$ and number of juveniles was $>25$ per vessel with a coefficient of variance $<50 \%$ in the control groups.

Enchytraeid survival and juvenile numbers did not differ between control groups exposed in the absence or presence of MF (t-test, $p>0.05$ ) although MF seemed to cause a slight decrease in juvenile numbers. Control groups in the $\mathrm{AgNP}$ and $\mathrm{AgNO}_{3}$ tests produced ( $\pm \mathrm{SE} ; \mathrm{n}=4$ ) $916 \pm 240$ and $891 \pm 88$ juveniles per vessel, respectively, while controls in the presence of MF produced $834 \pm 23$ and $758 \pm 82$ juveniles per vessel, respectively.

The LC/EC50 values and dose-response curves for Ag toxicity to enchytraeids are shown in Table 1 and Figure SI7, respectively. In the presence of MF, enchytraeid mortality caused by AgNP slightly increased, with an LC50 of $3080 \mathrm{mg} \mathrm{Ag} / \mathrm{kg}$ (Table 1). No difference in EC50 for AgNP was observed in the presence or absence of $\mathrm{MF}$ (GLR test, $\mathrm{X}_{\mathrm{df}=1}^{2}<3.84$, n.s.). For $\mathrm{AgNO}_{3}, \mathrm{MF}$ presence did not affect the results for survival or reproduction, with no differences between LC50 and EC50 values (GLR test, $\mathrm{X}^{2} \mathrm{df}=1<3.84$, n.s.).

\subsubsection{Ag bioaccumulation}

Body Ag concentrations of worms exposed to $\mathrm{AgNP}$ and $\mathrm{AgNO}_{3}$ can be found in Figure 2. In general, the enchytraeids accumulated higher Ag levels than the earthworms, but in both species body $\mathrm{Ag}$ concentrations increased with increasing exposure levels in the soil. Overall, the presence of MF did not affect Ag uptake in both worm species (t-test, $p>0.05$ ). Only in earthworms exposed to the highest concentration of AgNP (3200 mg Ag/ kg), the average Ag body concentration significantly decreased from $130 \mu \mathrm{g} / \mathrm{g}$ in the Ag treatment to $60 \mu \mathrm{g} / \mathrm{g}$ in the combination of AgNP and MF (t-test, $\mathrm{p}<0.05$ ).

\section{Discussion}




\subsection{Microplastic fiber influence on Ag toxicity}

The role and mode of action of the combined exposure to microplastics and contaminants is not fully understood (Ribeiro et al., 2019). In order to increase understanding on this topic, the influence of MF, at a realistic concentration, on the toxicity of $\mathrm{AgNP}$ and $\mathrm{AgNO}_{3}$ to earthworms and enchytraeids was assessed. For that, we compared EC50 values for Ag alone and in combination with MF. For reasons of time constraints, it was not possible to test different concentrations of MF, we therefore selected a fieldrelevant MF concentration.

Specific properties of NP are fairly well known to affect their toxicity to soil invertebrates (Makama et al., 2016; Shoults-Wilson et al., 2011a; Tourinho et al., 2012), and a wide range in LC/EC50 values can be found in the literature. For effects on reproduction, the EC50 for AgNP was $\sim 80 \mathrm{mg} \mathrm{Ag} / \mathrm{kg}$ in $E$. andrei (Schlich et al., 2013) and values ranging from 90 to $160 \mathrm{mg} / \mathrm{kg}$ were found in E. crypticus (Bicho et al., 2016; Topuz \& van Gestel, 2017). The EC50 values in our study were much higher than these values previously reported, indicating a lower toxicity of the PVP-coated AgNP used in the current study. For $\mathrm{AgNO}_{3}$, our $\mathrm{LC} / \mathrm{EC} 50$ values were in close agreement with previous studies on earthworms (Diez-Ortiz et al., 2015; Schlich et al., 2013) and enchytraeids (Bicho et al., 2016; Topuz \& van Gestel, 2017).

The exposure to MF alone may also have affected the reproduction of earthworms and enchytraeids, as shown by the decrease in reproduction in the MF controls. A significant decrease in number of juveniles of E. crypticus exposed to polyester fibers (4000-24000 $\mu \mathrm{m}$ in length) in LUFA 2.2 soil at $0.5 \%(\mathrm{w} / \mathrm{w})$ has been observed (Selonen et al., 2020). And a dose-related decrease in reproduction of E. crypticus exposed to nylon particles (13-150 $\mu \mathrm{m}$ in length) has been reported, with an EC50 of $100 \mathrm{~g} / \mathrm{kg}(10 \% \mathrm{w} / \mathrm{w})$ (Lahive et al., 2019). Our study, however, is the first indication of microplastic effects on earthworm reproduction. Two previous studies have found no effect of polyethylene microplastics on the reproduction of $E$. andrei (Rodríguez-Seijo et al., 2017) and Lumbricus terrestris (Huerta Lwanga et al., 2016). What the reason is of the decreased juvenile earthworms' numbers in the MF only exposed groups remains unclear, and needs further investigation.

The presence of MF in soil significantly increased the toxicity of AgNP to earthworm reproduction. A nano-specific effect is suggested, since the toxicity of $\mathrm{AgNO}_{3}$ (used as the ionic counterpart) was not affected by MF presence. Although the mechanisms behind these results remain unclear, it can be speculated that AgNP and MF acted in an additive/synergistic way. The dissolution of Ag ions into soil pore water is considered the main cause of toxicity to earthworm reproduction, which can affect cocoon production (Shoults-Wilson et al., 2011a; van der Ploeg et al., 2014) and juvenile survival (Diez-Ortiz et al., 2015; Schlich et al., 2013). The effects of microplastics on soil organisms, on the other hand, are mostly related to physical damages. Besides food dilution (Huerta Lwanga et al., 2016), the ingestion of microplastics can result in gastrointestinal tissue damage in earthworms (Baeza et al., 2020; RodríguezSeijo et al., 2017). External lesions are also possible when earthworms are exposed through dermal contact (Baeza et al., 2020). At the cellular level, microplastics can induce increased oxidative stress (Prendergast-Miller et al., 2019; Zhou et al., 2020) and DNA damage (Jiang et al., 2020). It is most likely 
that all these subtle effects could affect energy allocation and, therefore, have some impact on reproduction. To our knowledge, this is the first report on the combined effects of microplastics and contaminants on earthworm reproduction. Previous studies have mainly assessed effects on earthworm bioaccumulation, survival and/or weight change (Hodson et al., 2017; Gaylor et al., 2013; Wang et al., 2019a, 2019b; Zhou et al., 2020). Reproduction is a more sensitive endpoint than survival and weight change. Therefore, we encourage more research on the joint effects of microplastics and contaminants in earthworms, using reproduction as an endpoint.

The FTIR analysis of organisms can be used as a biomarker for assessing toxicity (Aja et al., 2014). Metal (Aja et al., 2014; Andre et al., 2010; Muthukaruppan, 2015) and microplastic exposures (RodríguezSeijo et al.; 2017) have been found to change the biochemical profile in earthworms. In our study, the highest intensity in the peaks from the FTIR spectra was found in earthworms exposed to the combination of MF and AgNP (3200 mg Ag/kg) (Figure 1). These peaks mostly indicated an increase in protein (3600-3000 $\left.\mathrm{cm}^{-1}\right)$ and lipid contents $\left(3000-2800 \mathrm{~cm}^{-1}\right)$. In addition, other less intensive changes were observed (mainly between 1230 and $550 \mathrm{~cm}^{-1}$ ), suggesting changes in carbohydrates, proteins and nucleic acids (Zohdi et al., 2015). Overall, these alterations can be related to the production of immunoprotective molecules as a stress-response mechanism in the earthworms (Rodríguez-Seijo et al., 2017). Moreover, the increase in protein levels could be an indicator of metal binding proteins (i.e., metallothionein). Metallothionein is induced in response to $\mathrm{AgNP}$ and $\mathrm{AgNO}_{3}$ exposure in earthworms (Hayashi et al., 2013; Patricia et al., 2017; Tsyusko et al., 2012). And more recently, polyester MF were also found to increase the metallothionein expression in the earthworm L. terrestris (Prendergast-Miller et al., 2019).

Unlike the results for earthworms, the presence of MF in soil had little or no influence on Ag toxicity to enchytraeids. This discrepancy between the two species could be explained by, but not limited to, exposure time and MF size. First, the longer exposure time could have increased the possibility of detecting any effect caused by the interactions between Ag and MF in the earthworm reproduction test. In addition, earthworms are able to ingest larger particles in comparison to enchytraeids (Coleman \&Wall, 2015), and therefore, earthworms were able to ingest a broader range of MF sizes. Lahive et al. (2019) showed the importance of particle size on the ingestion and toxicity of microplastics in E. crypticus. Enchytraeids ingested greater quantities of smaller $(10-20 \mu \mathrm{m})$ than of larger microplastic particles (60$150 \mu \mathrm{m})$, which resulted in a higher toxicity of the smaller particles towards enchytraeid reproduction. As the particle size of MF in our exposures ranged from 50 to $3000 \mu \mathrm{m}$, we can assume that the enchytraeids ingested less MF than the earthworms.

Moreover, we cannot ignore the differences in Ag storage between the two species. Enchytraeids did accumulate considerably more Ag than did the earthworms, which indicates a higher storage capacity. Enchytraeidae seem to have a greater capacity to accumulate essential and non-essential metals than Lumbricidae (Santorufo et al. 2012; Tosza et al., 2010; van Vliet et al., 2006). When exposed to metalcontaminated soil, E. crypticus was also found to accumulate higher levels of $\mathrm{Cu}, \mathrm{Pb}$ and $\mathrm{Zn}$ compared to 
E. andrei (Santorufo et al. 2012). This species-specific physiological difference could help explaining why AgNP effects differed with and without MF for earthworms but not for enchytraeids.

\subsection{Microplastic fiber influence on Ag bioaccumulation}

In general, no significant difference in Ag bioaccumulation was observed when MF were added to the soil. The only exception was observed in earthworms exposed to the highest AgNP concentration (3200 mg $\mathrm{Ag} / \mathrm{kg}$ ), where the presence of MF decreased internal Ag concentrations. Microplastics can both increase and decrease bioavailable fractions of contaminants, as shown in previous studies. A decrease in porewater concentration of hydrophobic organic compounds (HOCs) led to a decrease in bioaccumulation in Eisenia fetida exposed in soil containing polyethylene (PE) and polystyrene (PS) microplastics ( $31 \%$ DW) (Wang et al., 2019b). Moreover, the bioaccumulation of arsenic $(40 \mathrm{mg} \mathrm{As} / \mathrm{kg})$ in the earthworm Metaphire californica decreased when polyvinyl chloride (PVC) microplastics (0.2\% DW) were added to the soil (Wang et al., 2019a). The presence of PVC microplastic seemed not to affect the speciation of arsenic in soil, but rather to decrease the proportion of more soluble and bioavailable species in the earthworm gut and tissue. On the contrary, polypropylene microplastics $\left({ }^{3} 0.03 \% \mathrm{DW}\right)$ increased internal $\mathrm{Cd}$ concentration in E. fetida. Cd concentration in worms increased with increasing microplastic concentration in soil and was positively correlated with microplastic ingestion (Zhou et al., 2020). The authors concluded that $\mathrm{Cd}$ adsorbed to the microplastics and desorbed in the gut after ingestion of microplastics by the worms.

The effects of microplastics on bioaccumulation depend on the chemical affinity between microplastics and contaminants (Tourinho et al., 2019). The adsorption of Ag onto microplastics is very likely to occur in aquatic systems in both ionic (Kalčíková et al., 2020; Khan et al., 2015) and nanoparticle forms (Li et al., 2020). However, there is no literature available regarding terrestrial systems yet. From our results, we can conclude that, for a microplastic concentration of $0.01 \%$ DW, differences in bioaccumulation could only be observed at an extremely high Ag soil concentration.

Furthermore, Ag porewater concentrations were similar in soils with or without MF (Table SI2). The absence of a strong effect of MF on porewater concentrations could be due to the fact that porewater extraction occurred only a couple of days after spiking. Perhaps this short time period was not enough for detecting a decrease in Ag porewater concentration when adding MF to soils. MF concentration may, however, also have been too low to significantly affect Ag porewater concentrations, which are dominated by the Ag binding to soil organic matter (Levard et al., 2012).

In either case, porewater concentrations could not explain the increase in AgNP toxicity to earthworms with the addition of MF to soil. One possible explanation is that MF altered Ag speciation which increased the concentration of bioavailable and toxic fractions of $\mathrm{Ag}$. It is known that AgNP continuously release Ag ions into the porewater with time (Diez-Ortiz et al., 2015; van der Ploeg et al., 2014). The sorption kinetics and dissolution rate of AgNP in soil could have been affected by MF, perhaps not leading to a higher porewater concentration but rather to a higher flux of $\mathrm{Ag}$ in the pore water, e.g. from the soil through pore water to the animals. 
Finally, it should be highlighted that soil invertebrates can store Ag fractions which do not contribute to toxicity (Diez-Ortiz et al., 2015; Tourinho et al., 2016). In fact, many authors have concluded that body concentration is not a good indicator of Ag toxicity in earthworms (Schlich et al., 2013; Diez-Ortiz et al., 2015; van der Ploeg et al., 2014; Shoults-Wilson et al., 2011b) and enchytraeids (Topuz \& van Gestel, 2017). Therefore, it is not surprisingly that internal Ag concentrations did not fully explain the toxicity outcomes in our study.

\section{Conclusions}

The continuous input of MF to the soil compartment is undoubted. Here, we showed that MF in soil can cause adverse effects on soil invertebrates at a relatively low concentration. These effects included changes in the biochemical composition of earthworms and a slight decrease in the reproductive success of both earthworms and enchytraeids. Moreover, MF presence did affect the toxicity of $\mathrm{AgNP}$ and $\mathrm{AgNO}_{3}$. MF may lower the bioavailable Ag fraction due to sorption, which, however, occurred only at high concentrations of $\mathrm{Ag}$ in the soil. Nevertheless, it did not result in a decrease in toxicity; the presence of MF, in fact, enhanced the toxicity of AgNP to the earthworms. For enchytraeids, Ag toxicity seemed to be less affected by MF presence, which is probably related to the shorter exposure period together with a lower MF ingestion by the enchytraeids. Based on the present results, we can therefore conclude that MF should be a major concern when considering its effects alone and the combined effects with other chemicals in soils.

\section{Declarations}

\section{Acknowledgments}

This work was supported by the European Structural and Investment Funds, OP RDE-funded project 'CHEMFELLS4UCTP' (No. CZ.02.2.69/0.0/0.0/17_050/0008485) and the Ministry of Education, Youth and Sports of the Czech Republic and the European Union (European Structural and Investment Funds Operational Programme Research, Development and Education) in the frames of the project "Modular platform for autonomous chassis of specialized electric vehicles for freight and equipment transportation", Reg. No. CZ.02.1.01/0.0/0.0/16_025/0007293. Thanks are due to FCT/MCTES for the financial support to CESAM (UIDP/50017/2020+UIDB/50017/2020), through national funds.

\section{Declarations}

Data Availability

All data generated or analysed during this study are included in this published article (and its supplementary information files)

Animal Research (Ethics) 
Not applicable

Consent to Participate (Ethics)

Not applicable

Consent to Publish (Ethics)

Not applicable

Clinical Trials Registration

Not applicable

Author Contribution

All authors contributed to the study conception and design. Material preparation, data collection and analysis were performed by Paula S. Tourinho, VSSL Prasad Talluri, Andraž Dolar, Rudo Verweij, Jiř́ Chvojka, and Alena Michalcová. The first draft of the manuscript was written by Paula S. Tourinho and all authors commented on previous versions of the manuscript. All authors read and approved the final manuscript.

Conflict of Interest

The authors have no conflicts of interest to declare that are relevant to the content of this article

Funding

This work was supported by the European Structural and Investment Funds, OP RDE-funded project 'CHEMFELLS4UCTP' (No. CZ.02.2.69/0.0/0.0/17_050/0008485) and the Ministry of Education, Youth and Sports of the Czech Republic and the European Union (European Structural and Investment Funds Operational Programme Research, Development and Education) in the frames of the project "Modular platform for autonomous chassis of specialized electric vehicles for freight and equipment transportation", Reg. No. CZ.02.1.01/0.0/0.0/16_025/0007293.

\section{References}

Aja, M., Jaya, M., Vijayakumaran, N. K. \& Hubert, J. I., 2014. FT-IR spectroscopy as a sentinel technology in earthworm toxicology. Spectrochimica Acta Part A: Molecular and Biomolecular Spectroscopy 120: 534541

Andre, J., King, R. A., Stürzenbaum, S. R., Kille, P., Hodson, M. E. \& Morgan, A. J., 2010. Molecular genetic differentiation in earthworms inhabiting a heterogeneous $\mathrm{Pb}$-polluted landscape. Environmental Pollution 158: $883-890$ 
Bicho, R. C., Ribeiro, T., Rodrigues, N. P., Scott-Fordsmand, J. J. \& Amorim, M. J. B., 2016. Effects of Ag nanomaterials $(\mathrm{NM} 300 \mathrm{~K})$ and $\mathrm{Ag}$ salt $\left(\mathrm{AgNO}_{3}\right)$ can be discriminated in a full life cycle long term test with Enchytraeus crypticus. Journal of Hazardous Materials 318: 608-614

Browne, M. A., Crump, P., Niven, S. J., Teuten, E., Tonkin, A., Galloway, T. \& Thompson, R., 2011. Accumulation of microplastic on shorelines worldwide: sources and sinks. Environmental Science and Technology 45: 9175-9179

Coleman, D. C. \& Wall, D. H., 2015. Soil fauna: occurrence, biodiversity, and roles in ecosystem function, in: Paul, E. A. (Ed.), Soil Microbiology, Ecology and Biochemistry. Academic Press, San Diego, 111-150

Cornelis, G., Kirby, J. K., Beak, D., Chittleborough, D. \& McLaughlin, M. J., 2010. A method for determination of retention of silver and cerium oxide manufactured nanoparticles in soils. Environmental Chemistry 7: 298-308

de Souza Machado, A. A., Lau, C. W., Till, J., Kloas, W., Lehmann, A., Becker, R. \& Rillig, M. C., 2018. Impacts of microplastics on the soil biophysical environment. Environmental Science and Technology 52: 9656-9665

Dholakiya B., 2012. Unsaturated polyester resin for specialty applications, in: Saleh, H. E.M. (Ed.), Polyester. IntechOpen, London, 167-202

Diez-Ortiz, M., Lahive, E., George, S., Ter Schure, A., van Gestel, C. A. M., Jurkschat, K., Svendsen, C. \& Spurgeon, D. J., 2015. Short-term soil bioassays may not reveal the full toxicity potential for nanomaterials; bioavailability and toxicity of silver ions $\left(\mathrm{AgNO}_{3}\right)$ and silver nanoparticles to earthworm Eisenia fetida in long-term aged soils. Environmental Pollution 203: 191-198

Durán, N., Marcato, P. D., De Souza, G. I. H., Alves, O. L. \& Esposito, E., 2007. Antibacterial effect of silver nanoparticles produced by fungal process on textile fabrics and their effluent treatment. Journal of Biomedical Nanotechnology 3: 203-208

Fuller, S. \& Gautam, A., 2016. A procedure for measuring microplastics using pressurized fluid extraction. Environmental Science and Technology 50: 5774-5780

Gaylor, M. O., Harvey, E. \& Hale, R. C., 2013. Polybrominated diphenyl ether (PBDE) accumulation by earthworms (Eisenia fetida) exposed to biosolids-, polyurethane foam microparticle-, and penta-BDEamended soils. Environmental Science and Technology 47: 13831-13839

Geyer, R., Jambeck, J. R. \& Law, K. L., 2017. Production, use, and fate of all plastics ever made. Science advances 3: e1700782

Gies, E. A., LeNoble, J. L., Noël, M., Etemadifar, A., Bishay, F., Hall, E. R. \& Ross, P. S., 2018. Retention of microplastics in a major secondary wastewater treatment plant in Vancouver, Canada. Marine Pollution 
Hayashi, Y., Heckmann, L. H., Simonsen, V. \& Scott-Fordsmand, J. J., 2013. Time-course profiling of molecular stress responses to silver nanoparticles in the earthworm Eisenia fetida. Ecotoxicology and Environmental Safety 98: 219-226

Hernandez, E., Nowack, B. \& Mitrano, D. M., 2017. Polyester textiles as a source of microplastics from households: a mechanistic study to understand microfiber release during washing. Environmental Science and Technology 51: 7036-7046

Hodson, M. E., Duffus-Hodson, C. A., Clark, A., Prendergast-Miller, M. T. \& Thorpe, K. L., 2017. Plastic bag derived-microplastics as a vector for metal exposure in terrestrial invertebrates. Environmental Science and Technology 51: 4714-4721

Horton, A. A., Svendsen, C., Williams, R. J., Spurgeon, D. J. \& Lahive, E. (2017a) Large microplastic particles in sediments of tributaries of the River Thames, UK - Abundance, sources and methods for effective quantification. Marine Pollution Bulletin 114: 218-226

Horton, A. A., Walton, A., Spurgeon, D. J., Lahive, E. \& Svendsen, C. (2017b) Microplastics in freshwater and terrestrial environments: evaluating the current understanding to identify the knowledge gaps and future research priorities. Science of the Total Environment 586: 127-141

Huerta Lwanga, E., Gertsen, H., Gooren, H., Peters, P., Salánki, T., van der Ploeg, M., Besseling, E., Koelmans, A. A. \& Geissen, V., 2016. Microplastics in the terrestrial ecosystem: implications for Lumbricus terrestris (Oligochaeta, Lumbricidae). Environmental Science and Technology 50: 2685-2691

Jiang, X., Chang, Y., Zhang, T., Qiao, Y., Klobučar, G. \& Li, M., 2020. Toxicological effects of polystyrene microplastics on earthworm (Eisenia fetida). Environmental Pollution 259: 113896

Kalčíková, G., Skalar, T., Marolt, G. \& Kokalj, A. J., 2020. An environmental concentration of aged microplastics with adsorbed silver significantly affects aquatic organisms. Water Research 175: 115644

Khan, F. R., Syberg, K., Shashoua, Y. \& Bury, N. R., 2015. Influence of polyethylene microplastic beads on the uptake and localization of silver in zebrafish (Danio rerio). Environmental Pollution, 206: 73-79

Lahive, E., Walton, A., Horton, A. A., Spurgeon, D. J. \& Svendsen, C., 2019. Microplastic particles reduce reproduction in the terrestrial worm Enchytraeus crypticus in a soil exposure. Environmental Pollution, 225: 113174

Levard, C., Hotze, E. M., Lowry, G. V \& Brown Jr, G. E., 2012. Environmental transformations of silver nanoparticles: impact on stability and toxicity. Environmental Science and Technology 46: 6900-6914

Li, P., Zou, X., Wang, X., Su, M., Chen, C., Sun, X. \& Zhang, H., 2020. A preliminary study of the interactions between microplastics and citrate-coated silver nanoparticles in aquatic environments. Journal of 
Mitrano, D. M., Rimmele, E., Wichser, A., Erni, R., Height, M. \& Nowack, B., 2014. Presence of nanoparticles in wash water from conventional silver and nano-silver textiles. ACS Nano 8: 7208-7219

Monikh, F. A., Vijver, M. G., Guo, Z., Zhang, P., Darbha, G. K. \& Peijnenburg, W. J. G. M., 2020. Metal sorption onto nanoscale plastic debris and trojan horse effects in Daphnia magna: Role of dissolved organic matter. Water Research 186: 116410

Muthukaruppan, G. (2015) Heavy metal induced biomolecule and genotoxic changes in earthworm Eisenia fetida. Invertebrate Survival Journal 12: 237-245

Ng, E. L., Lwanga, E. H., Eldridge, S. M., Johnston, P., Hu, H. W., Geissen, V. \& Chen, D., 2018. An overview of microplastic and nanoplastic pollution in agroecosystems. Science of the Total Environment 627: 13771388

Nizzetto, L., Futter, M. \& Langaas, S., 2016. Are agricultural soils dumps for microplastics of urban origin?. Environmental Science and Technology 50: 10777-10779

OECD (2004a) Test No. 222: Earthworm Reproduction Test (Eisenia fetida/ Eisenia andrei). In OECD Guidelines for the Testing of Chemicals. Organisation for Economic Co-operation and Development, Paris, 2004

OECD (2004b) Test No. 220: Enchytraeid Reproduction Test. In OECD Guidelines for the Testing of Chemicals. Organisation for Economic Co-operation and Development, Paris, 2004

Patricia, C. S., Nerea, G. V., Erik, U., Elena, S. M., Eider, B. \& Manu, S., 2017. Responses to silver nanoparticles and silver nitrate in a battery of biomarkers measured in coelomocytes and in target tissues of Eisenia fetida earthworms. Ecotoxicology and Environmental Safety 141: 57-63

Pirc, U., Vidmar, M., Mozer, A. \& Kržan, A., 2016. Emissions of microplastic fibers from microfiber fleece during domestic washing. Environmental Science and Pollution Research 23: 22206-22211

Prendergast-Miller, M. T., Katsiamides, A., Abbass, M., Sturzenbaum, S. R., Thorpe, K. L. \& Hodson, M. E., 2019. Polyester-derived microfibre impacts on the soil-dwelling earthworm Lumbricus terrestris.

Environmental Pollution 251: 453-459

Ribeiro, F., O'Brien, J. W., Galloway, T. \& Thomas, K. V., 2019. Accumulation and fate of nano- and microplastics and associated contaminants in organisms. TrAC Trends in Analytical Chemistry 111: 139-147

Rodríguez-Seijo, A., Lourenço, J., Rocha-Santos, T. A. P., da Costa, J., Duarte, A. C., Vala, H. \& Pereira, R., 2017. Histopathological and molecular effects of microplastics in Eisenia andrei Bouché. Environmental Pollution 220: 495-503 
Rosu, D., Cascaval, C. N. \& Rosu, L., 2008. Synthesis and characterization of some composites with bioactive properties on the basis of vinyl ester resins. e-Polymers 8: 1-10

Scheurer, M. \& Bigalke, M., 2018. Microplastics in Swiss floodplain soils. Environmental Science and Technology 52: 3591-3598

Schlich, K., Klawonn, T., Terytze, K. \& Hund-Rinke, K., 2013. Effects of silver nanoparticles and silver nitrate in the earthworm reproduction test. Environmental Toxicology and Chemistry 32: 181-188

Selonen, S., Dolar, A., Kokalj, A. J., Skalar, T., Dolcet, L. P., Hurley, R., \& van Gestel, C. A. M., 2020. Exploring the impacts of plastics in soil - The effects of polyester textile fibers on soil invertebrates. Science of the Total Environment, 700: 134451

Shoults-Wilson, W. A., Reinsch, B. C., Tsyusko, O. V., Bertsch, P. M., Lowry, G. V. \& Unrine, J. M., 2011a. Role of particle size and soil type in toxicity of silver nanoparticles to earthworms. Soil Science Society of America Journal 75: 365-377

Shoults-Wilson, W. A., Reinsch, B. C., Tsyusko, O. V, Bertsch, P. M., Lowry, G. V \& Unrine, J. M., 2011b. Effect of silver nanoparticle surface coating on bioaccumulation and reproductive toxicity in earthworms (Eisenia fetida). Nanotoxicology 5: 432-444

Sillanpää, M. \& Sainio, P., 2017. Release of polyester and cotton fibers from textiles in machine washings. Environmental Science and Pollution Research 24: 19313-19321

Santorufo, L., van Gestel, C. A. M. \& Maisto, G., 2012. Ecotoxicological assessment of metal-polluted urban soils using bioassays with three soil invertebrates. Chemosphere, 88: 418-425

Topuz, E. \& van Gestel, C. A. M., 2017. The effect of soil properties on the toxicity and bioaccumulation of Ag nanoparticles and Ag ions in Enchytraeus crypticus. Ecotoxicology and Environmental Safety 144: 330-337

Tosza, E., Dumnicka, E., Niklińska, M. \& Rożen, A., 2010. Enchytraeid and earthworm communities along a pollution gradient near Olkusz (southern Poland). European Journal of Soil Biology 46: 218-224.

Tourinho, P. S., van Gestel, C. A. M., Lofts, S., Svendsen, C., Soares, A. M. V. M. \& Loureiro, S., 2012. Metalbased nanoparticles in soil: Fate, behavior, and effects on soil invertebrates. Environmental Toxicology and Chemistry 31: 1679-1692

Tourinho, P. S., Kočí, V., Loureiro, S. \& van Gestel, C. A. M., 2019. Partitioning of chemical contaminants to microplastics: Sorption mechanisms, environmental distribution and effects on toxicity and bioaccumulation. Environmental Pollution 252: 1246-1256

Tsyusko, O. V., Hardas, S. S., Shoults-Wilson, W. A., Starnes, C. P., Joice, G., Butterfield, D. A. \& Unrine, J. M., 2012. Short-term molecular-level effects of silver nanoparticle exposure on the earthworm, Eisenia fetida. 
USEPA, 2009. Targeted national sewage sludge survey statistical analysis report. Appendix 1. Washington, DC.: United States Environmental Protection Agency Office of Water. EPA-822-R-08-018 Van der Ploeg, M. J. C., Handy, R. D., Waalewijn-Kool, P. L., van den Berg, J. H. J., Herrera Rivera, Z. E., Bovenschen, J., Molleman, B., Baveco, J. M., Tromp, P. \& Peters, R. J. B., 2014. Effects of silver nanoparticles (NM-300K) on Lumbricus rubellus earthworms and particle characterization in relevant test matrices including soil. Environmental Toxicology and Chemistry 33: 743-752

Van Vliet, P. C. J., Didden, W. A. M., Van der Zee, S. E. A. T. M. \& Peijnenburg, W. J. G. M., 2006. Accumulation of heavy metals by enchytraeids and earthworms in a floodplain. European Journal of Soil Biology 42: S117-S126

Wang, H.-T., Ding, J., Xiong, C., Zhu, D., Li, G., Jia, X.-Y., Zhu, Y.-G. \& Xue, X.-M., 2019a. Exposure to microplastics lowers arsenic accumulation and alters gut bacterial communities of earthworm Metaphire californica. Environmental Pollution 251: 110-116

Wang, J., Coffin, S., Sun, C., Schlenk, D. \& Gan, J., 2019b. Negligible effects of microplastics on animal fitness and HOC bioaccumulation in earthworm Eisenia fetida in soil. Environmental Pollution 249: 776784

Whiteley, C. M., Dalla Valle, M., Jones, K. C. \& Sweetman, A. J., 2013. Challenges in assessing release, exposure and fate of silver nanoparticles within the UK environment. Environmental Science: Processes \& Impacts 15: 2050-2058

Wigger, H., Hackmann, S., Zimmermann, T., Köser, J., Thöming, J. and von Gleich, A., 2015. Influences of use activities and waste management on environmental releases of engineered nanomaterials. Science of the Total Environment, 535: 160-171

Zhang, G. S., Zhang, F. X. \& Li, X. T., 2019. Effects of polyester microfibers on soil physical properties: Perception from a field and a pot experiment. Science of the Total Environment 670: 1-7

Zhou, Y., Liu, X. \& Wang, J., 2020. Ecotoxicological effects of microplastics and cadmium on the earthworm Eisenia foetida. Journal of Hazardous Materials 392: 122273

Zohdi, V., Whelan, D. R., Wood, B. R., Pearson, J. T., Bambery, K. R. \& Black, M. J., 2015. Importance of tissue preparation methods in FTIR micro-spectroscopical analysis of biological tissues: 'Traps for new users'. PLOS ONE 10: e0116491

Zubris, K. A. V. \& Richards, B. K., 2005. Synthetic fibers as an indicator of land application of sludge. Environmental Pollution 138: 201-211 


\section{Tables}

Table 1: Effects of AgNP and $\mathrm{AgNO}_{3}$ on the survival (LC50) and reproduction (EC50) of the earthworm Eisenia andrei and the enchytraeid Enchytraeus crypticus after 28 and 21 days of exposure in LUFA 2.2 soil, respectively. Results for the exposure of Ag alone or combined with $100 \mathrm{mg} / \mathrm{kg}$ of polyester microplastic fibers (MF) are presented. LC50s and EC50s are based on nominal concentrations in $\mathrm{mg} \mathrm{Ag} / \mathrm{kg}$ dry soil, and were obtained using Probit analysis and a 3-parameter logistic model, respectively. The 95\% confidence intervals are presented in brackets.

\begin{tabular}{lccccc}
\hline Species & & AgNP & AgNP + MF & $\mathrm{AgNO}_{3}$ & $\mathrm{AgNO}_{3}+\mathrm{MF}$ \\
\hline Eisenia andrei & LC50 & $>3200$ & $>3200$ & 240 & 410 \\
& & & & $($ n.d.) & $(280-780)$ \\
& EC50 & 450 & $165 *$ & 38 & 40 \\
& & $(250-645)$ & $(50-285)$ & $(27-50)$ & $(13-67)$ \\
\hline Enchytraeus crypticus & LC50 & $>3200$ & 3080 & 130 & 100 \\
& & & $(2375-4520)$ & $(110-160)$ & $(55-200)$ \\
& EC50 & 880 & 1020 & 90 & 73 \\
& & $(60-1700)$ & $(450-1600)$ & $(63-120)$ & $(35-113)$ \\
\hline
\end{tabular}

*Significant difference in EC50 values for AgNP in the absence and presence of microplastic fibers (GLR test, $\mathrm{X}_{\mathrm{df}=1}^{2}>3.84, \mathrm{p}<0.05$ ). n.d.: no confidence interval could be calculated.

\section{Figures}

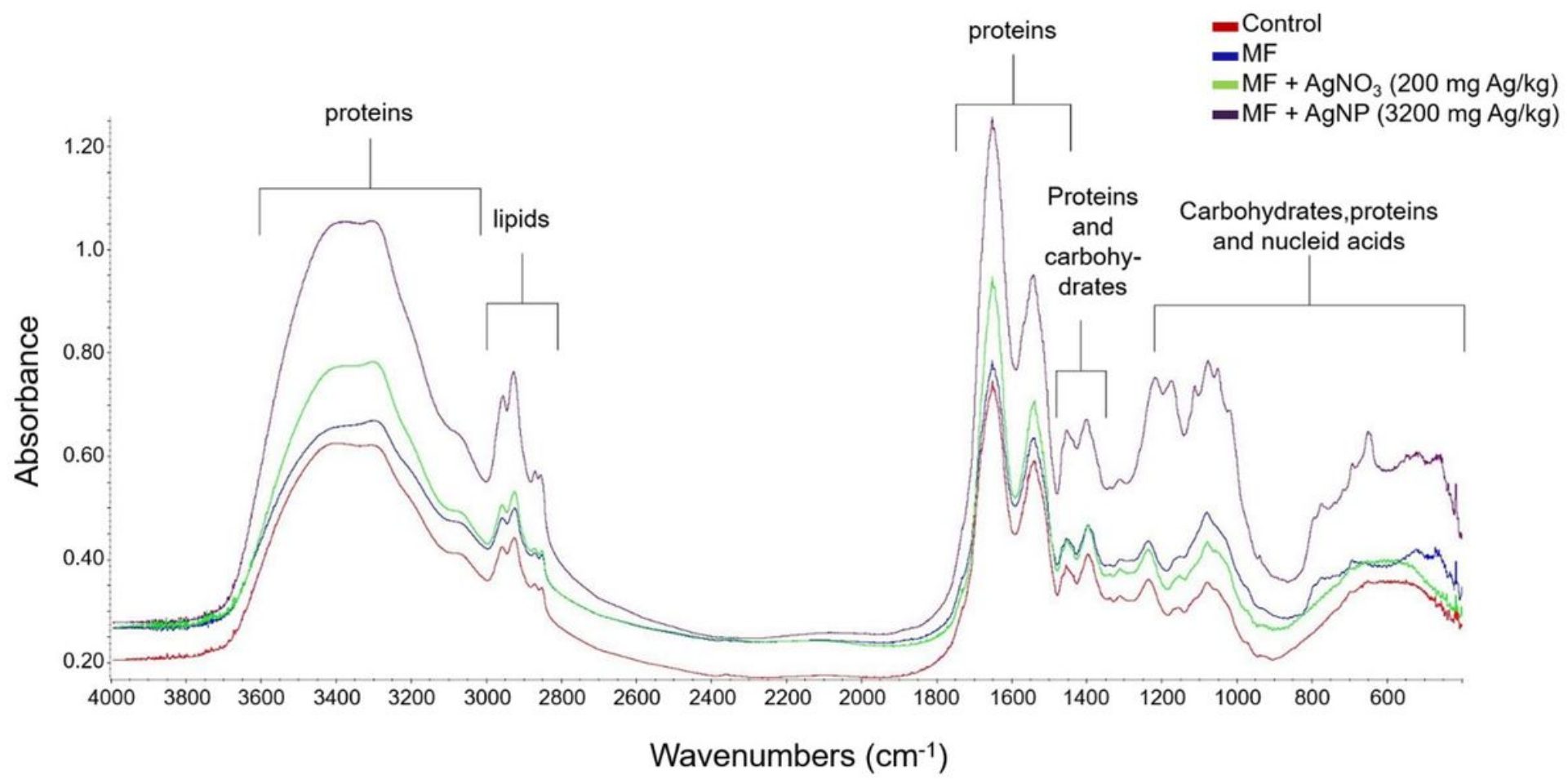


Figure 1

Fourier Transform Infrared (FTIR) spectra of the earthworm Eisenia andrei exposed to control LUFA 2.2 soil, soil spiked with polyester microplastic fiber (MF) alone, and the combination of MF and AgNO3 or AgNP. Bands were described based on Muthukaruppan (2015), Rodríguez-Seijo et al. (2017) and Zohdi et al. (2015).

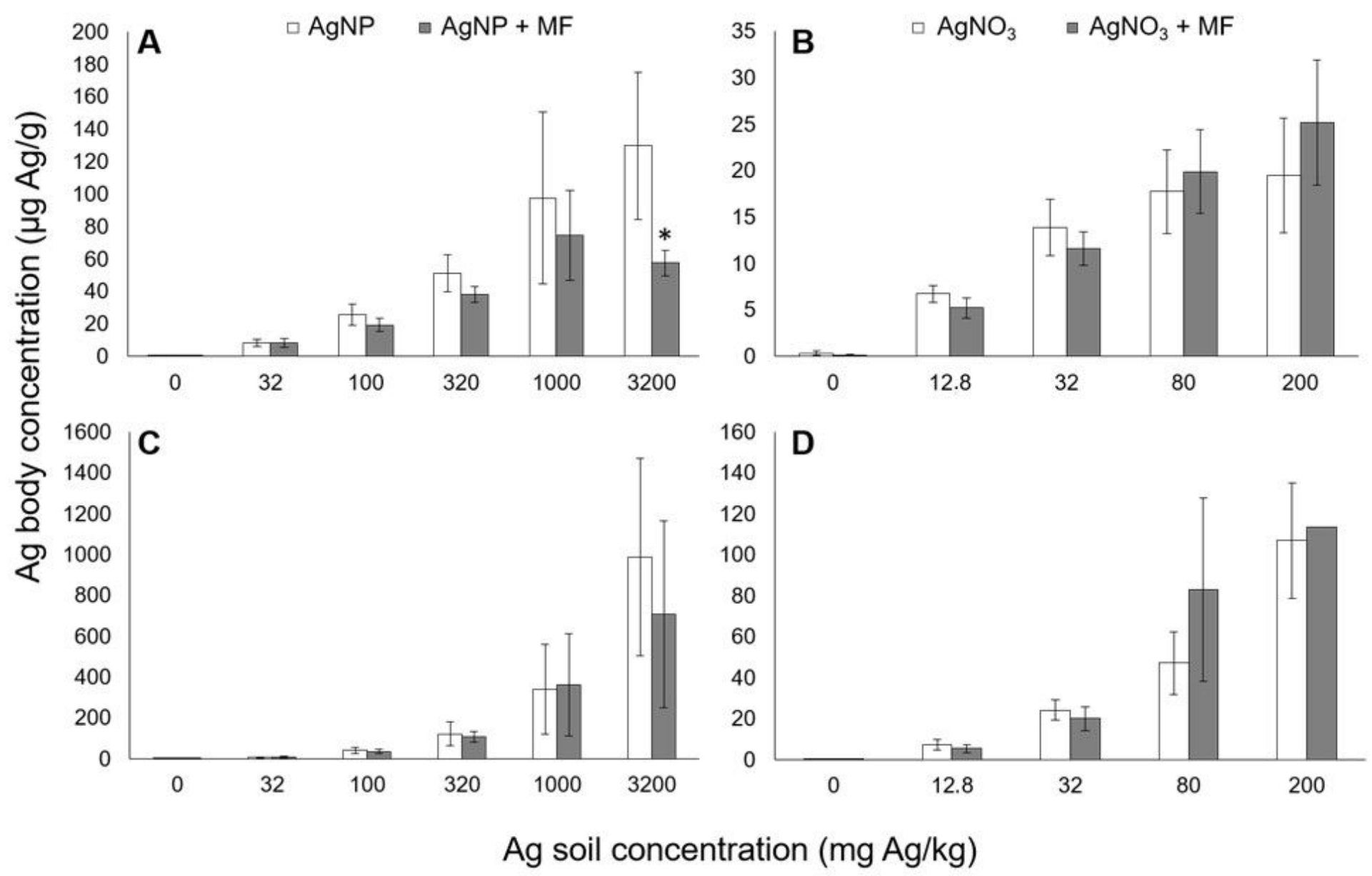

Figure 2

Ag body concentrations (mean $\pm S D$ ) in the earthworm Eisenia andrei ( $A$ and $B$ ) and the enchytraeid Enchytraeus crypticus ( $C$ and D) exposed to AgNP (left) and AgNO3 (right) in LUFA 2.2 soil for 28 and 21 days, respectively. Organisms were exposed to these Ag forms alone (white columns) and in the combination of $\mathrm{Ag}$ and polyester microplastic fibers (MF) (gray columns). Asterisk represents differences in Ag body concentrations between worms exposed to only $\mathrm{Ag}$ and the combination of $\mathrm{Ag}$ and MF within the same Ag exposure level (t-test, $p<0.05)$.

\section{Supplementary Files}

This is a list of supplementary files associated with this preprint. Click to download.

- SupportinginformationAgMFsoilmanuscript.pdf 